\title{
Life tables of Bracon hebetor Say (Hymenoptera: Braconidae) and its Host; Palpita unionalis Hübner (Lepidoptera: Pyralidae)
} Amany N. Mansour ${ }^{1}$; A. I. Imam ${ }^{1}$; Walaa G. Ibrahim ${ }^{2}$; A. G. Abdel-Rahman ${ }^{1}$; E. A. Agamy $^{3}$ and H. F. Dahi ${ }^{2}$

${ }^{1}$ Plant Protection Department, Desert Research Center, El Matariya, Cairo, Egypt.

${ }^{2}$ Plant Protection Research Institute, Agricultural Research Center, Dokki, Giza, Egypt.

${ }^{3}$ Biological Control Laboratory, Faculty of Agriculture, Cairo University, Giza, Egypt. Corresponding author: amanynmansour@yahoo.com

\begin{abstract}
The reproductive performance of the ecto-larval parasitoid Bracon hebetor Say (Hymenoptera: Braconidae) as well as its host; the olive leaf moth Palpita unionalis Hübner (Lepidoptera: Pyralidae) was studied in the laboratory at $27 \pm 2{ }^{\circ} \mathrm{C}$. The $P$. unionalis is an important pest on olives, and also feeds on other host plants from the family Oleaceae. The estimated life table parameter was the net reproductive rate $\left(\mathrm{R}_{\mathrm{o}}\right)$, the mean generation time $(T)$, the intrinsic rate of natural increase $\left(\mathrm{r}_{\mathrm{m}}\right)$ and the finite rate of increase $(\lambda)$. This parameter was represented by $68.28,20.01,0.15,1.17$ for $B$. hebetor and $68.54,32.09,0.13$ and 1.14 for $P$. unionalis, respectively. Females of the parasitoid lived for $21.8 \pm 1.97$ days. The average number of eggs oviposited by females was $365.6 \pm 44.94$. Immature survival from egg to adult was $41 \%$. Sex ratio of wasp progeny (females/total) was 0.46 . $P$. unionalis females lived on average for $9.10 \pm 0.35$ days and deposited $179.98 \pm 22.64$ eggs/female. Survival rate for immature was $68 \%$. Sex ratio of progeny was 0.55 . The results concluded of this study can be used to improve mass rearing programs and support in oculative release applications of $B$. hebetor against the olive leaf moth.
\end{abstract}

Keywords: Olive, Bracon hebetor, Palpita unionalis, Life tables, Biological control

\section{INTRODUCTION}

Olive and fig orchards constitute the main agricultural domain at the Egyptian Northwestern Coastal (NWC) area. Olive tree through its developmental schedule face having more than one economic insect pest species. Olive leaf moth, $P$. unionalis is one of the highly devastating pests especially for nurseries. Larvae attack tender leaves, particularly those of terminal twigs. Newly hatched larvae usually feed on the parenchyma of the lower surface of the leaves, drying the upper epidermis, which becomes brown. Where, in nurseries, larvae may devour young leaves and apical buds, causing stunted growth of the plants. (Athanassiou et al., 2004; Kovanci and Kumral, 2004 and Kumral et al., 2007).

Bracon hebetor is a hymenopteran member of Family Braconidae. Beyond the natural capability of its females to parasitize caterpillar larvae and lay its eggs on the larval body surface (ectoparasitoid, gregarious and Idiobiont species) (Eliopoulos and Stathas, 2008), a lot of biological control investigators at the last decades concerned this candidate through a series of studies to shed light on its biology (Yu et al., 2003), on ecology (Eliopoulos and Stathas, 2008),on parasitization capacity (Cline and Press, 1990), on host species and density (Taylor, 1988; Gulel and Gunduz, 2004 and Yu et al., 2003), investigation on effect of prevailing environmental conditions (Farghaly and Ragab, 1984 and Thanavendan and Jeyarani, 2010). The intended aim of their studies was to enroll $B$. hebetor in the proposed programs dedicated for combating caterpillar larvae. Through reviewing the previous studies it was worth to note that, although the shortage in the field data regarding the combating of pyralid larvae with $B$. hebetor, few of which concerned the life table of the wasp and its host (Cline and Press, 1990; Grieshop et al., 2006, Eliopoulos and Stathas, 2008).

Life table study is often a simple way for keeping track of births, deaths and reproductive output in a population of interest. Moreover, over the past few decades, life tables have become an indispensable tool for biological control workers, especially in evaluating a parasitoid against a host under various climate conditions and host habitats (Birch 1948, Jervis and Copland 1996). In addition, demographic data could help to assess the potential of population increase on olive, and may help to explain why $P$. unionalis outbreaks occur in olive groves (Kumral et al., 2007).

Bracon hebetor is one of the endemic (naturally occurring) larval parasitoid at the NWC olive orchards. Through her study, Mansour (2012) recorded this larval parasitoid in the olive orchards for the first time and a series of experimental trails had been done to explore its potential activity against olive leaf moth, $P$. unionalis.

Accordingly, the intended goal of the current work is dedicated for study the different biological parameters (the life table parameters) regarding both $B$. hebetor and its field host ( $P$. unionalis), which include the net reproductive rate, the intrinsic rate of natural increase and the finite rate of increase. Such parameters are considered as crucial data that should be clarified to facilitate the engagement of such beneficial candidate in a scheduled augmentation program in order to combat larval stage of $P$. unionalis.

\section{MATERIALS AND METHODS}

To attain the intended objective, more than one step had been covered that include laboratory rearing of the greater wax moth, Galleria mellonella Linnaeus (as the factitious host for $B$. hebetor), B. hebetor and the field host, $P$. unionalis. All these insects had been subjected to scheduled rearing programs at the insectaries of Plant Protection Department, Desert Research Center at $27^{\circ} \mathrm{C}$ and $75 \% \mathrm{RH}$.

Insect cultures:

1-Olive leaf moth; $P$. unionalis

The initial source of the olive leaf moth, $P$. unionalis, has been collected from the infested young 
olive trees at the olive orchard in El-Kasr district that locate at the western direction of Matrouh Governorate. Larvae were transferred to rearing jars ( 2 pounds plastic jars) in the laboratory and daily provided with tender olive leaves. Pupae were transferred to clean Petri dishes till adult emergence. Emerged moths were sexed and transferred with a ratio of 2 males: 5 females to new plastic jar that charged by small cotton piece saturated with $10 \%$ sugar solution for moth nourishment and olive tender branch as egg deposition sites. Moths were transferred to new jars as the eggs started to hatch. The emerged neonate larvae were frequently provided with tender olive till pupation.

2-Greater wax moth; Galleria mellonella Linnaeus Artificial diet that previously described and published by Bhatnagar and Bareth (2004) were provided to G. mellonella larvae. Corrugated papers were added to the rearing jars as pupation sites. Pupae was collected and transferred to new plastic jars and left for adult emergence. Eggs are usually deposited on the rim of the jar that is covered with strip of paper. The cover of the jar where moths prefer to lay their eggs in between the double layer tissue paper is frequently replaced from time to other. Both strip papers and tissue papers are collected and transferred to new jars provided with artificial diet for larval feeding after egg hatchability.

\section{3-The larval parasitoid; B. hebetor}

The initial field collection of the wasp had been done from the olive groves at Matrouh Governorate (Mansour, 2012). Adult wasps are sexed and transferred to a clean Petri dish charged by small honey droplet for wasp nutrition and 1 full grown $G$. mellonella larvae for egg deposition. Each Petri dish had been tightly sealed with para-film. After egg deposition, each parasitoid couple had been transferred to a new Petri dish similar to that previously described for new egg deposition. Parasitoid eggs were left to hatch and their larvae feed on the host then pupation occurred in the near vicinity. Adults were collected as they emerge and transferred to new Petri dishes.

Experimental design:

Thirty seven $B$. hebetor females aged $<1$ day old had been individually separated in clean Petri dishes to act as replicates (i.e., 1 female/ 1 Petri dish). Each Petri dish had been supplied by newly emerged Bracon male for mating, small honey droplet for wasps' nourishment and one full grown $P$. unionalis larva as an egg deposition and larval feeding site. Each 24 hours, the parasitoid couple had been transferred to new Petri dish charged by new $P$. unionalis larva and small honey droplet. Such process had been repeated till the death of the parasitoid female. For each female, the daily number of its deposited eggs, the number of hatched larvae, the number of emerged progeny and their sex ratio had been recorded. In addition, fifty newly emerged $P$. unionalis females were daily observed for egg deposition till their death. Numbers of deposited eggs, hatched larvae, pupae and progeny emergence were recorded. Such obtained data had been formulated as an input data and entered in the 48 Basic computer program for calculating the life table parameters (Birch, 1948 and Abo-Setta et al., 1986).

\section{RESULTS AND DISCUSSION}

Table (1) showed that $P$. unionalis moths have lived for $9.10 \pm 0.35$ days. During their life time, $179.98 \pm 22.64$ eggs were deposited. These data are coincided with Kumral et al. (2007) they recorded female longevity of the same insect to be 11.6, 9.9, 10.7 days when larvae reared on olive, ash and jasmine, respectively. They recorded average number of eggs oviposited by adults females as 390.3, 194.7, 321.8 eggs when reared on the same plant hosts, respectively. Data showed that survival rate of different immature averaged 0.68. Kumral et al. (2007) recorded survival percentage of immature stages reared on olive leaves as $73 \%$. They added that immature mortality generally was high in larval stages and mortality was low among instars 3-6. After adult emergence, Data indicated that the sex ratio (female/total) was 0.55 .

Average longevity of $B$. hebetor females was $21.8 \pm 1.97$ days on the full grown larvae of $P$. unionalis (Table 1). In line with our data, Yu et al., (2003) recorded $20.88 \pm 0.97$ days on Plodia interpunctella Hübner (Lepidoptera: Pyralidae). Results obtained in the present study showed high reproductive rate of $B$. hebetor. Where the average deposited eggs per female was $365.6 \pm 44.94$. Hagstrum and Smittle (1977) stated that an average-size female that has encountered a host every day will have a lifetime fecundities of 250-350 eggs. Immature survival rate was 0.41 and the emerged progeny sex ratio was 0.46 . Ghimire (2010) reported that a parasitoid survival to adult stage on $G$. mellonella was almost 50\%. Many authors reported similar trends of the progeny sex ratio of the parasitoid. Reinert and King (1971) observed the sex ratio on Plodia. interpunctella to be around 52\%. Noah and Dan (1973) and (Rotary and Gerling, 1973) found the sex ratio of $B$. hebetor at $25^{\circ} \mathrm{C}$ with Ephestia kuehniella Zeller (Lepidoptera: Pyralidae) as a host, to be 39 and 66\%, respectively. Yu et al. (2003) stated that the overall progeny sex ratio was approximately 0.5 . Parasitoid progeny sex ratios in other studies have been variable, ranging from a male bias to strongly female bias progeny (Ghimire and Phillips, 2010; Jamil et al., 2015; Alam et al., 2016).

Table 1. Biological parameters of olive leaf moth; $\boldsymbol{P}$. unionalis and its larval parasitoid, $B$. hebetor.

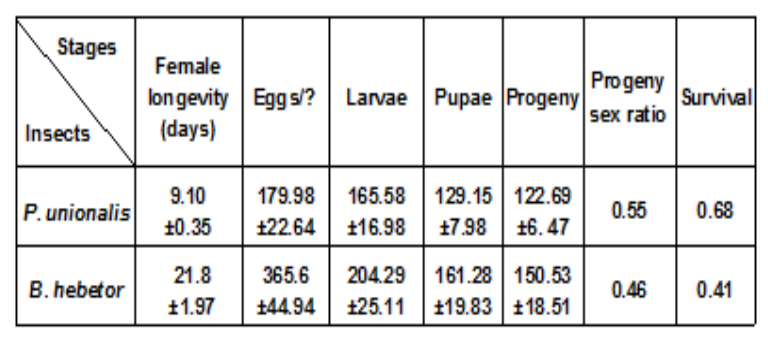

Data illustrated in Table (2) gave clarified insights about the life table parameters that had been measured for the parasitoid and its field host. Upon shed 
light on $P$. unionalis, Table (2) stated that its net reproductive rate (Ro) recorded about 68.54. As this parameter refers to the reproductive capability of the intended candidate (egg laying capacity), so the reproductive capacity of $P$. unionalis on olive plant is considered of moderate type. Where, through the field observations of the olive orchards under NWC conditions, it is easy to observe that the economic damage due to the olive leaf moth is of localized occurrence and mainly targeted olive seedlings and nurseries. In this field of study, Kumral et al. (2007) noticed that $P$. unionalis exhibited the highest Ro value on olive comparing with both Ash and Jasmine. The second considered demographic parameter was the intrinsic rate of increase (rm) that gave an impression about the mode of population increase (Birch 1948). The recorded $\mathrm{rm}$ value for $P$. unionalis (about 0.13 ) indicated that the population increase of $P$. unionalis on olive leaves was of exponential mode ( $\mathrm{rm}>0)$ ). Similar findings had been stated by Kumral et al. (2007) on $P$. unionalis, Greenberg et al. (2001) on Spodoptera exigua Hübner (Lepidoptera: Noctuidae) and Hansen et al. (2004) on Sitotroga cerealella Olivier (Lepidoptera: Gelechiidae).

The finite rate of increase $(\lambda)$ behaved similar trend of $r_{m}$ value. Where, the calculated value of Lambda $(\lambda)$ (about 1.14 i.e., $\lambda>1$ ) referred to an increment in $P$. unionalis population. Accordingly, the last two parameters should be considered by the field monitors to schedule or track a precise monitoring system for the olive leaf moth population in order to be ready for any population outbreak. Where, the field monitoring of its population through the last two years under the Egyptian NWC olive orchard conditions and due to the warmer winter seasons during this period than the previous ones, the monitoring team succeeded to record $P$. unionalis caterpillars attacking olive tender leaves and seedlings till December month (unpublished data). The last measured demographic parameter was the mean generation time ( $\mathrm{T})$. According to the current findings, $P$. unionalis is able to build up one generation at about 32.1 days. Our results regarding $\mathrm{T}$ value was similar to that stated by Kumral et al. (2007) who calculated $\mathrm{T}$ values for $P$. unionalis as $35.3,32.99$ and 36.16 days on olive, ash and jasmine hosts, respectively. Khaghaninia and Pourabad (2009) estimated the mean developmental time from the egg to the adult of the same pest at $27^{\circ} \mathrm{C}$ to be 34.9 days.

Table 2. Demographic parameters of olive leaf moth; $P$. unionalis and its larval parasitoid, $B$. hebetor.

\begin{tabular}{lcc}
\hline Parameters & P. unionalis & B. hebetor \\
\hline Net Reproductive Rate $\left(\mathrm{R}_{\mathrm{o}}\right)$ & 68.5364 & 68.2824 \\
Mean Generation Time $(\mathrm{T})$ & 32.0910 & 20.0147 \\
Intrinsic Rate of Increase $\left(\mathrm{r}_{\mathrm{m}}\right)$ & 0.1317 & 0.1541 \\
Finite Rate of Increase $(\lambda)$ & 1.1408 & 1.1666 \\
\hline
\end{tabular}

The second part of Table (2) concerned with the demographic parameters of the larval parasitoid $B$. hebetor that had been reared on its field host, $P$. unionalis. The net reproductive rate $\left(\mathrm{R}_{\mathrm{o}}\right)$ and the intrinsic rate of increase $\left(r_{m}\right)$ of our intended parasitoid were about 68.28 and 0.15 , respectively. Through exploring such values on other pyralid hosts, SeungHun et al. (1999) stated that, both $\mathrm{R}_{\mathrm{o}}$ and $\mathrm{r}_{\mathrm{m}}$ values of $B$. hebetor on Plodia. interpunctella recorded about 136.2 and 0.29 , respectively. Although the value of $r_{m}$ in the present study is lower than others, Huffaker et al. (1977) stated that, the natural enemy should have an $r_{m}$ high enough to offset that part of the pest's $r_{m}$ that is not negated by parasitism. Moreover, the other two parameters as shown in Table (2) were the finite rate of $B$. hebetor population increase $\lambda$ and the mean generation time $(\mathrm{T})$. The calculated values for both parameters were about 1.17 and 20.01 , respectively that referred to the effective role that could be played by the parasitoid to induce successful parasitization and turn down the population of olive leaf moth. One of the very supportive issues for that conclusion was the shorter mean generation time of $B$. hebetor than that of its host (P. unionalis) by about 10 days that gave the priority for the parasitoid for producing about one generation and half at the same time that required for its host to attain one generation. Eliopoulos and Stathas (2008) recorded the mean generation time for $B$. hebetor to be 20.14 and $\lambda$ to be 1.13 when reared on Plodia. interpunctella. This was graphically illustrated in Figs. $1 \& 2$.

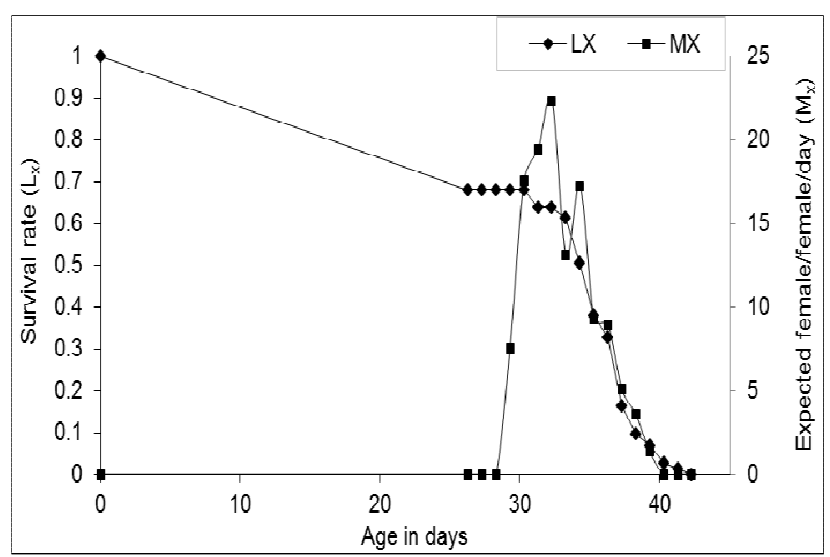

Fig 1. Expected female/female/day $\left(M_{x}\right)$ and survival rate $\left(\mathrm{L}_{\mathrm{x}}\right)$ of $P$. unionalis.

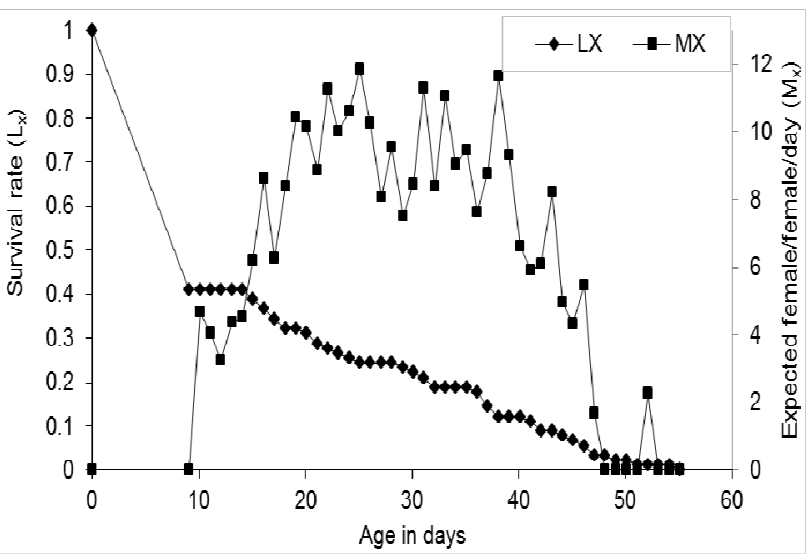

Fig 2. Expected female/female/day $\left(M_{x}\right)$ and survival rate $\left(\mathrm{L}_{\mathrm{x}}\right)$ of $B$. hebetor.

Expected female/female/day $\left(\mathrm{M}_{\mathrm{x}}\right)$ and survival rate $\left(\mathrm{L}_{\mathrm{x}}\right)$ for the parasitoid and its host are presented in Figs. $1 \& 2$. It is obvious that survival curve of the pest 
followed type I of survival (where most of the population reaches maturity and death occur following oviposition). On the other hand, type III was followed in the case of parasitoid survival. Where, parasitoid survival as adults was the dominant.

In conclusion, the present study indicated that demographic parameters are useful for the assessment of $B$. hebetor suitability to combat the olive leaf moth. Therefore, an effort should be made for the application of field releases of the parasitoid in olive orchards because they not only live long but also produce more progeny that can play a significant role in olive groves.

\section{REFERENCES}

Abou-Setta, M. M.; Sorrell, R. W. and Childers, C. C. (1986): Life 48 a basic computer program to calculate life table parameters for an insect or mite species. Fla. Entomol., 69: 690-697.

Alam MS, Alam MZ, Alam SN, Miah MRU, Mian MIH, Hossain MM (2016) Mass rearing of Bracon hebetor (Hym.: Braconidae) on wax moth, Galleria mellonella (Lepidoptera: Pyralidae) with varying density of parasitoid and the host. J. Crop Prot. 5:39-48.

Athanassiou, C. G.; Kavallieratos, N. G. and Mazomenos, B. E. (2004): Effect of trap type, trap color, trapping location, and pheromone dispenser on captures of male Palpita unionalis (Lepidoptera: Pyralidae). J. Econ. Entomol., 97 (2): 321-329.

Bhatnagar, A. and Bareth, S. S. (2004): Development of low cost, high quality diet for greater wax moth, Galleria mellonella (Linnaeus). Indian J. Ent., 66 (3): 251-255.

Birch, L. C. (1948): The intrinsic rate of natural increase of an insect population. J. Anim. Ecol., 17: 15 - 26.

Cline, L. D. and Press. J. W. (1990): Reduction in almond Moth (Lepidoptera: Pyralidae) infestations using commercial packaging of foods in combination with the parasitic wasp, Bracon hebetor (Hymenoptera: Braconidae). J. Econ. Entomol., 83: 1110 - 1113.

Eliopoulos, P. A. and Stathas, G. J. (2008): Life tables of Habrobracon hebetor (Hymenoptera: Braconidae) Parasitizing Anagasta kuehniella and Plodia interpunctella (Lepidoptera: Pyralidae): Effect of Host Density. J. Econ. Entomol., 101(3): $982-988$.

Farghaly, H. T.; and Ragab, Z. A. (1984): Relationship between relative humidity and adult biology of Bracon hebetor Say. Bull. Soc. Entomol. Egypt, 65: $131-136$.

Ghimire, MN, Phillips, TW (2010): Mass rearing of Habrobracon hebetor Say (Hymenoptera: Braconidae) on larvae of the Indian meal moth, Plodia interpunctella (Lepidoptera: Pyralidae): effects of host density, parasitoid density, and rearing containers. J Stored Prod Res 46:214-220.
Greenberg, S. M.; Sappington, T. W.; Legaspi, B. C.; Liu, T. X. and Setamou, M. (2001): Feeding and life history of Spodoptera exigua (Lepidoptera: Noctuidae) on different host plants. Ann. Entomol. Soc. America, 94 (4): 566 - 575.

Grieshop, M. J.; Flinn, P. W. and Nechols, J. R. (2006): Biological control of Indianmeal moth (Lepidoptera: Pyralidae) on finished stored products using egg and larval parasitoids. J. Econ. Entomol., 99: 1080 -1084.

Gulel, A. and Gunduz, E. A. (2004): The effect of host species and food types on longevity of Bracon hebetor Say. (Hymenoptera : Braconidae). Turk. Entomol. Derg., 28: 275 - 282.

Hagstrum, D. W. and Smittle, B. J. (1977): Host-finding ability of Bracon hebetor and its influence upon adult parasite survival and fecundity. Environ. Entomol. 6 (3): 437-439.

Hansen, L. S.; Skovgard, H. and Hell, K. (2004): Life table study of Sitotroga cerealella (Lepidoptera: Gelechiidae), a strain from West Africa. J. Econ. Entomol. 97 (4): 1484 - 1490.

Huffaker, C. B.; Luck, R. F. and Messenger, P. S. (1977): The ecological basis of biological control, 15th International Congress of Entomology, Entomological Society of America, College Park, MD, 560 - 586.

Jamil A.; Ul Abdin Z.; Arshad M.; Falabella P.; Abbas SK.; Tahir M.; Jamil A.; Manzoor A. and Shaina H. (2015): Multiple effects of host density on egg density and the sex ratio of progeny of Bracon hebetor Say. (Hymenoptera: Braconidae). Pakistan J. Zool. 47:455-460.

Jervis, M. A. and Copland, M. J. W. (1996): The life cycle, pp. 63 - 161. In M. A. Jervis and N.A.C. Kidd [eds.], Insect natural enemies - practical approaches to their study and evaluation. Chapman \& Hall, London, United Kingdom.

Khaghaninia, S. and Pourabad, R. F. (2009): Investigation on biology of olive leaf worm Palpita unionalis $\mathrm{Hb}$. (Lepidoptera: Pyralidae) in constant laboratory conditions. Mun. Ent. Zool., 4 (2): 320-326.

Kovanc1, B. and Kumral, N. A. (2004): Insect pests in olive groves of Bursa (Turkey). In: Proceedings of $5^{\text {th }}$ International Symposium on Olive Growing (Eds. Özkaya M.T., İzmir) p. 68.

Kumral, N. A.; Kovanci, B. and Akbudak, B. (2007): Life tables of the olive leaf moth, Palpita unionalis (Hübner) (Lepidoptera: Pyralidae), on different host plants. J. Biol. Environ. Sci., 1 (3): $105-110$.

Mansour, N. Amany (2012): Biocontrol studies on using Bracon sp. (Hymenoptera: Braconidae) to control lepidopterous pests infesting olive trees. $\mathrm{PhD}$ Thesis, Fac. Sci., Al-Azhar Univ., Egypt, 176 pp.

Noah, R. and Dan, G. (1973): The Influence of some external factors upon the sex ratio of Bracon hebetor Say (Hymenoptera: Braconidae). Environ. Entomol., 2 (1): 134-138. 
Reinert, J. A. and King, E. A. (1971): Action of Bracon hebetor Say a parasite on Plodia interpunctella at controlled density. Ann. Entomol. Soc. Am., 64: $1335-1340$.

Rotary, N. and Gerling, D. (1973): The influence of some external factors upon the sex ratio of Bracon hebetor Say. (Hymenoptera: Braconidae). Environ. Entomol., 2(1): 134-138.

Seung-Hun, Y.; Mun, I. I. R. and Hyun, J. N. (1999): Life History of Bracon hebetor (Hymenoptera: Braconidae) on Plodia interpunctella (Lepidoptera: Pyralidae) on a Dried Vegetable Commodity. J. Asia-Pacific Entomol., 2(2): 149-152.
Taylor, A. D. (1988): Host effects on larval competition in the gregarious parasitoid Bracon hebetor. J. Anim. Ecol., 57: 163 - 172.

Thanavendan, G. and Jeyarani, S. (2010): Effect of different temperature regimes on the biology of Bracon brevicornis Wesmael (Braconidae: Hymenoptera) on different host larvae. J. Biopesticides, 3 (2): 441 - 444.

Yu, S. H.; Ryoo, M. I.; Na, J. H. and Choi, W. I. (2003): Effect of host density and the sex ratio of progeny of Bracon hebetor (Hymneoptera: Braconidae). J. Stored Prod. Res., 39: 385 - 393.

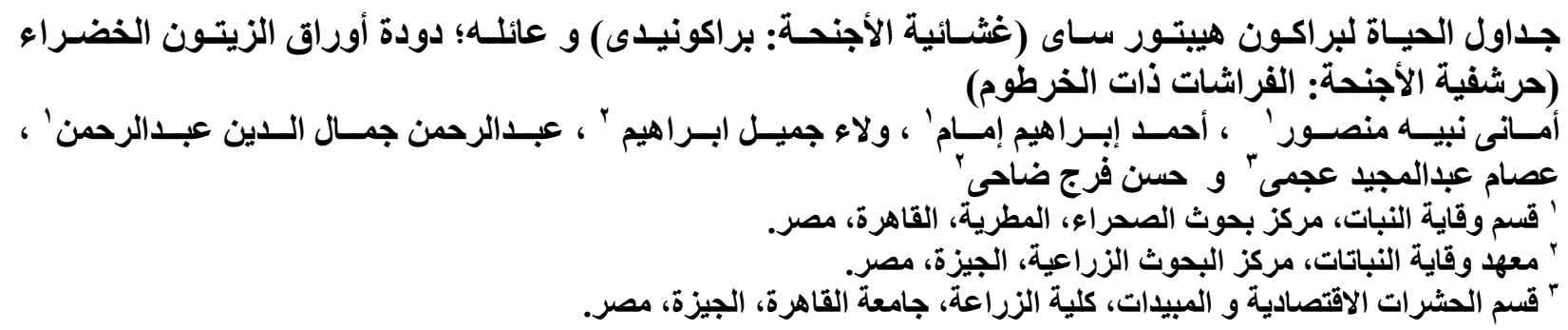

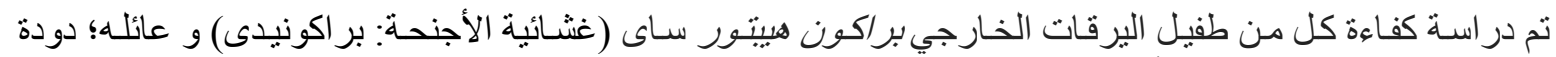

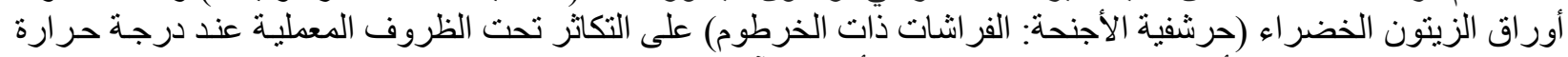

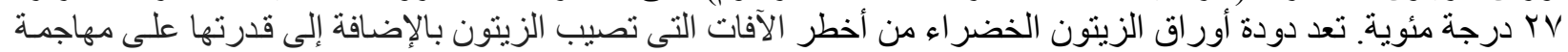

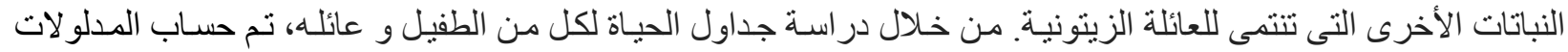

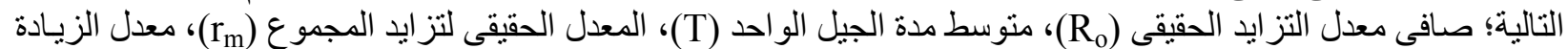

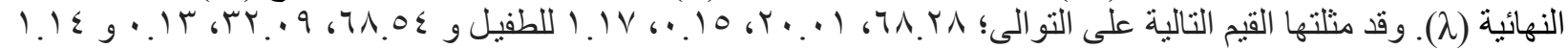

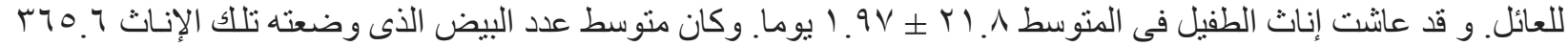

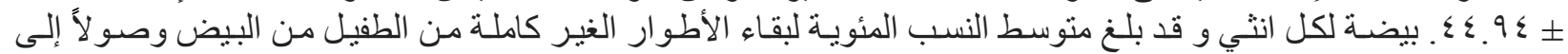

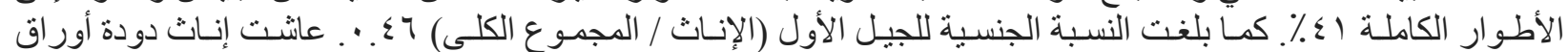

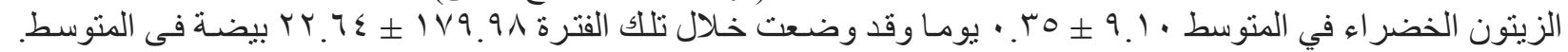

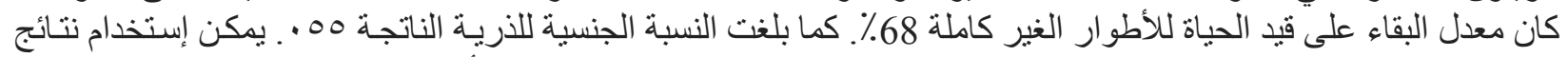

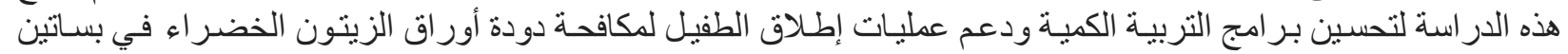

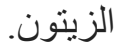
الكلمات الافتتاحية: الزيتون ، بر اكون هيبتور ، دودة أور اق الزينون الخضر اء ، جداول الحياة ، المكافحة البيولوجية . 